\title{
Qual o ensino médico eficaz? Os "quase doutores" do Espírito Santo dão sua opinião"
}

\author{
Ana Gláucea Quarto Silva ${ }^{1}$ \\ Carlos Carnelli Silva Demoner ${ }^{2}$ \\ Carlos Henrique Segall Junior ${ }^{3}$ \\ Daví Dias Pagotto ${ }^{4}$ \\ Sabrina Tiradentes Ferreira ${ }^{5}$
}

\section{Introdução}

No momento em que reitores, diretores, professores e pessoas direta ou indiretamente ligadas às Escolas Médicas se engajam no propósito de melhorar o ensino da Medicina em nosso país, qual tem sido a contribuição dos alunos do Espírito Santo à CINAEM (Comissão Interinstitucional Nacional de Avaliação do Ensino Médico)? Em nosso Estado, pequena e inexpressiva.

A proposta deste texto é analisar nossa realidade a partir dos anseios dos alunos de Medicina, sextanistas dos cursos de graduação em Medicina das Faculdades médicas do Espírito Santo - a Faculdade de Medicina da Universidade Federal do Espírito Santo (UFES) e a Escola de Medicina da Santa Casa de Misericórdia de Vitória (EMESCAM), a partir da pergunta: qual seria o ensino médico eficaz? Esperamos que os resultados deste trabalho possam ser úteis para as discussões desenvolvidas no âmbito do Projeto CINAEM, no qual acreditamos.

O estudo: desenvolvimento e resultados O estudo foi realizado com os objetivos: a) identificar estratégias mais eficientes para a solução de dificuldades e problemas apontados pelos alunos com relação ao modelo de ensino médico em vigência nos cursos de Medicina do Espírito Santo; b) fornecer subsídios à direção das Faculdades que possam auxiliar na construção de um modelo de ensino-aprendizagem mais condizente com as expectativas dos profissionais de saúde; c) definir, segundo a visão dos alunos, a qualidade do "terreno" no qual o Projeto CINAEM vem "plantando" suas "sementes", no sentido de que se possa traçar novos caminhos ou conservar as rotas até então seguidas.

\footnotetext{
* Este estudo teve por objetivo, mediante questionário apresentado aos alunos sextanistas do Curso de Graduação, levantar opiniões sobre o atual ensino adotado pelas Faculdades de Medicina do Espírito Santo para oferecer, aos gestores dessas instituições, dados de nossa realidade que possam contribuir para a construção de um modelo de ensino-aprendizagem mais adequado e compatível com as demandas sociais do setor saúde na sociedade contemporânea.

1,2,3,4,5 Acadêmicos da graduação do curso de Medicina da EMESCAM - Escola de Medicina da Santa Casa de Misericórdia de Vitória-ES. Orientador: Luís Renato da Silveira Costa, professor de Deontologia Médica e Coordenador do curso de Medicina da EMESCAM. Colaboradores: Paulo Bonates, professor de Psicologia Médica da EMESCAM e Renata Maria Teixeira Lengruber, acadêmica da graduação do curso de Medicina da EMESCAM.
} 
Foi utilizado um estudo de corte transversal com alunos sextanistas do curso de graduação em Medicina das escolas médicas do Espírito Santo. Utilizou-se, para tal, um questionário padrão, e foram realizadas entrevistas pessoais $e$ direcionadas. O estudo abrangeu $25 \%$ dos formandos em Medicina do ano de 1999, perfazendo um total de cinqüenta entrevistas, com vinte alunos da Universidade Federal do Espírito Santo (UFES) e trinta alunos da Escola de Medicina da Santa Casa de Misericórdia de Vitória (EMESCAM).

Os resultados obtidos, sintetizados abaixo, envolvem diferentes aspectos da formação $e$ atuação profissional.

Após o questionamento - por que fazer Medicina? - a grande maioria dos acadêmicos relatou o desejo de serem médicos como um sonho de infância, não se imaginando exercer outra profissão. Atribuem isto a uma pretensa aptidão e satisfação pessoal, ao fato de "poderem salvar vidas, curar e ajudar as pessoas, com base na ciência". Muitos alunos confessaram terem concretizado $e$ solidificado seus ideais dos "tempos de cursinho", aprendendo, no entanto, a encarar as limitações da profissão. Todos revelam amor pelo que fazem, paixão pela arte médica. A influência familiar também aparece como fator decisivo para a escolha da profissão. Curiosamente, foram poucos os que manifestaram anseio de grandes lucros financeiros, poder e "status". Poucos acreditam ter um futuro profissional $e$ financeiro garantido e outros mudaram de opinião a esse respeito, apesar de terem tido, no início do curso, esta impressão.

Ao descreverem seu processo de amadurecimento, relataram que foi gradativo $e$ ainda se encontram nesse processo, crescendo a cada nova experiência, a cada novo desafio. A maioria diz ter ultrapassado sozinho as barreiras $e$ as dificuldades; outros tiveram o auxílio de pessoas ligadas à Medicina. Reconhecem, entretanto, o isolamento em que se encontram, em relação ao mundo que os rodeia, em virtude de o curso de Medicina os absorver quase que totalmente, dificultando o convívio saudável com outras áreas do conhecimento humano. Quanto a estarem ou não preparados para exercer a Medicina as opiniões se dividem: uns categoricamente afirmaram que sim; outros acreditam que não e alegam falta de segurança, medo $e$ dependência de profissionais mais experientes.

Ao serem questionados sobre o atual modelo de saúde em vigência no país, usam frases do tipo: "estamos de mãos atadas"; "somos marionetes nas mãos dos que controlam o sistema". Possuem muitas dúvidas com relação ao SUS (Sistema único de Saúde). Aos que acham válidos os objetivos do SUS, juntam-se outros, mais revoltados, que expõem sua insatisfação.

Sobre a relação médico-paciente, a maioria diz descer dos degraus de um falso "Olimpo" e se colocar no lugar dos pacientes. Acreditam que o bom relacionamento médico-paciente é fundamental para o tratamento; obtêm maiores informações, a aceitação da medicação e melhoria do estado emocional do paciente.

Quanto ao currículo, todos acham importante o chamado currículo oculto, além da Faculdade, construído por meio do estágio em rede pública, monitorias, participação em concursos públicos, elaboração de trabalhos científicos, estudo de línguas e informática. Ressaltam, entretanto, que um "grande currículo" não é sinônimo de bom profissional.

Especificamente com relação à produção científica, observamos um divisor de águas. Os alunos da EMESCAM afirmaram que a produção em sua Faculdade deixa a desejar e que as poucas iniciativas existentes baseia-se no "peito e na raça", ou por incentivo de algum professor envolvido em tal prática. Já na UFES, os alunos consideram boas as oportunidades para a pesquisa e elaboração de trabalhos científicos. Todos concordam que o incentivo à pesquisa deve existir e seus 
parâmetros devem ser estabelecidos.

Sobre aspectos éticos, emocionais e psicológicos, alegaram conviver bem com a morte, com a cobrança familiar, e com outras ocorrências isoladas. Consideraram, contudo, ser muito grande o conflito interno vivido entre o saber e não poder fazer, entre aceitar sua incapacidade, suas limitações $e$ entender que, às vezes, a situação foge a seu controle.

Questionados sobre o PROVÃO, as opiniões se dividem. Um grupo considerou válido; outro não. Todos concordaram que é necessário definir o que realmente se pretende avaliar, se as escolas ou os alunos. Consideraram as questões mal elaboradas, mal distribuídas entre as disciplinas. Acreditam, em sua maioria, que o PROVÃO tem seu valor porque estimula as escolas médicas a prepararem melhor seus alunos, o que lhes pode ser útil nos concursos para residência médica.

A quase totalidade dos alunos entrevistados acredita ser necessária a residência médica porque a Faculdade não fornece os subsídios necessários ao exercício da prática médica; contudo, questionam os critérios para ingresso nesses programas.

Consideram os médicos brasileiros atuais submetidos a uma jornada excessiva de trabalho, com alto nível de "stress", recebendo baixa remuneração por seus serviços. Acreditam que os profissionais médicos perderam o "status" e o respeito que outrora gozavam na sociedade e que estes fatores contribuem para que se tenha um serviço de má qualidade e sujeito a erros cada vez mais freqüentes.

Com relação ao corpo docente atualmente existente nas Faculdades, os alunos acreditam que há uma minoria de bons professores. Reclamam da falta de interesse em ensinar, de didática, de atualização, da pouca utilização dos atuais recursos didáticos disponíveis, levando a aulas ineficazes no sentido do aprendizado.
Questionados sobre a melhor forma de os professores estimularem o aprendizado, todos manifestaram interesse por aulas teóricas de qualidade, preferencialmente curtas e por práticas associadas á teoria. Reivindicam maior critério nas avaliações, sugerem elaboração de provas claras $e$ objetivas, que privilegiem aspectos genéricos da atividade profissional e não "rodapés de livros"; maior discussão de casos clínicos, estímulo à pesquisa, realização de debates ou seminários. Alguns manifestaram interesse em estudar de forma autodidata $e$, neste caso, o professor atuaria como orientador de estudo e esclarecedor de dúvidas. A maioria dos entrevistados não concorda com o atual método de avaliação adotado pelo curso, citando inclusive que as notas não medem o conhecimento de ninguém, nem sinalizam para uma prática profissional de qualidade.

Todos os entrevistados apontaram a falta de recursos dos hospitais-escola como o principal problema enfrentado pelas entidades. Somam-se a estas deficiências, bibliotecas velhas, pouco diversificadas $e$ insuficientes para atender a demanda existente.

Com informações obtidas daqueles que estão terminando o curso e viveram o processo de formação acadêmica recentemente, e sem a pretensão de uma interpretação crítica dos dados levantados, apuramos pontos positivos e negativos do curso médico atual. Acreditamos que os gestores e professores, ouvindo os alunos e analisando criticamente suas sugestões, poderão investir na melhoria do ensino médico, colocando no mercado de trabalho profissionais mais competentes. Já se sabe que existem inúmeras falhas no processo ensino-aprendizagem das escolas médicas. $\mathrm{O}$ que fazer para melhorar? Qual o melhor caminho a ser seguido? A hora é esta. 


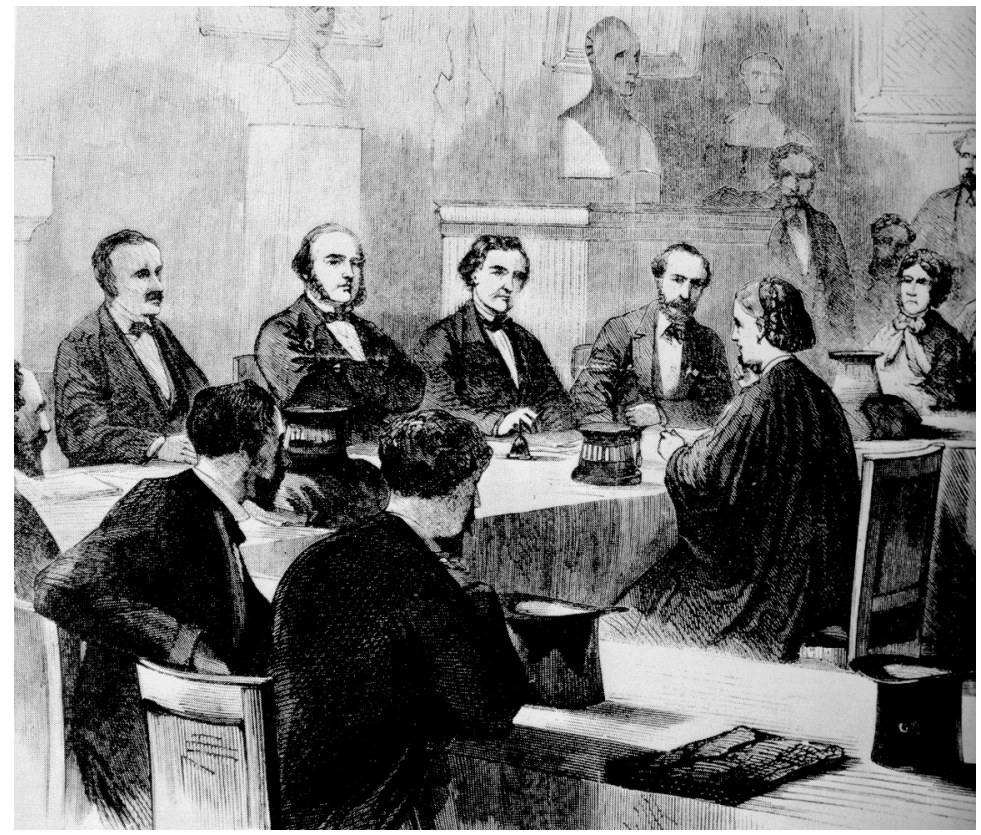

Miss Garrett before the boards of Medical Examiners at Paris, 1870. Biblioteca Nacional de Medicina, Bethesda. 